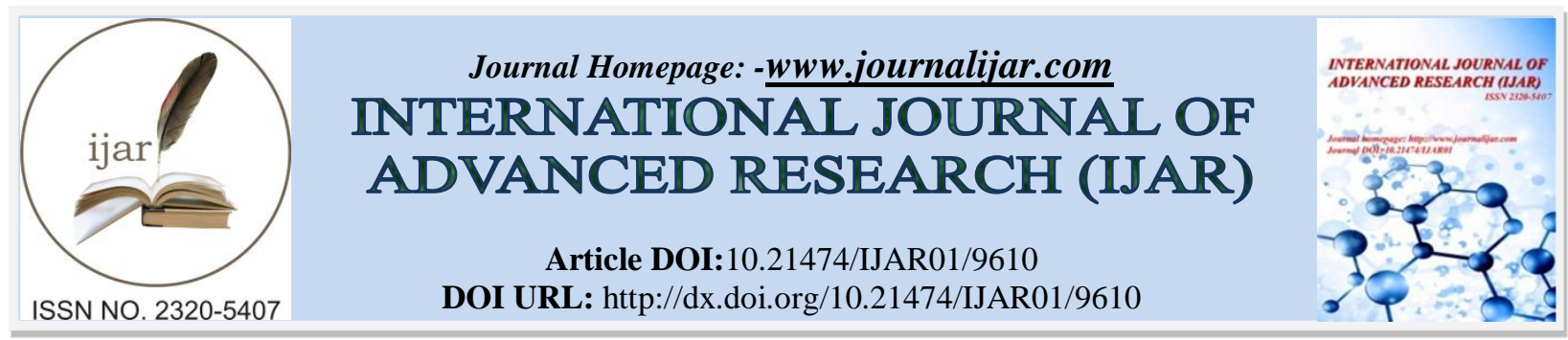

RESEARCH ARTICLE

\title{
EFFECTIVENESS OF HIGH GRADE MAITLAND MOBILIZATION TECHNIQUE IN PATIENT WITH IDIOPATHIC ADHESIVE CAPSULITIS OF SHOULDER JOINT.
}

\section{A. K. M rezwan ${ }^{1}$, Selim hossain ${ }^{1}$, Md. Ashraful alam ${ }^{2}$, Md. Azmol hossain ${ }^{3}$, Md. Mizanur Rahman ${ }^{4}$ and} Samia Jannat ${ }^{5}$.

1. Lecturer- Gono Bishwabidyalay Nolam, Savar, Dhaka.

2. Rehab specialist-Centre for disability in development,Ulail, Savar, Dhaka.

3. Chief consultant-PT,Eastern care hospital ltd, Dhaka.

4. Consultant and HOD - PT,Nightingale Medical Collage hospital,Dhaka, iris 820 .

5. Student of Physiotherapy (BPT)Gono Bishwabidyalay. Savar .Dhaka.

\section{Manuscript Info}

Manuscript History

Received: 20 June 2019

Final Accepted: 22 July 2019

Published: August 2019

\section{Keywords}

High Grade Maitland Mobilization, Conventional Physiotherapy Techniques, Idiopathic Adhesive Capsulitis, Visual analogue scale (VAS), Shoulder Pain and Disability Index (SPADI).
Abstract

Objective: The idiopathic adhasive capsulitis of shoulder joint is very common disease estimated to be 2 to 5 percent of the general population and aim of the study was to determine the effectiveness of high grade Maitland mobilization technique in patients with idiopathic adhesive capulitis of shoulder joint. Methods: Total of 40 subjects diagnosed with idiopathic shoulder adhesive capsulitis were selected and randomly allocated into two groups. In group A $(n=20)$ subjects were treated with high grade Maitland mobilization technique, whereas subjects in group $B(n=20)$ received conventional physiotherapy technique. Shoulder Pain and Disability Index (SPADI) and Visual Analogue Scale (VAS) were used for outcome measure. Pain and functional disability were recorded before and after the treatment. Total duration of the study was 1 year; data were analyzed by SPSS and student $\mathrm{t}$ test. Result: The mean age group of the study was $45.63 \pm 8.018$ years with a range from 35 to 65 years, More of the respondents were female $(62.5 \%)$ and married $(92.5 \%)$. Secondary level of education completed (35\%) of respondents were more and people who are housewife they are mostly affected (40\%) by this condition. deformity level were very less just only $12.5 \%$ and Right shoulder is maximally affected $(82.5 \%)$. Most of the respondents suffered by continuous pain (55\%) and Pain were more at morning (75\%). Muscle atrophy was found in $95 \%$ and more of the respondents were visited doctors $(67.5 \%)$. History of trauma were $(7.5 \%)$ and Diabetes Mellitus were (32.5\%) of the respondent, this study also found highly significant association between muscle deformity and types of pain $(\mathrm{p} \leq 0.02)$. Study also analysis the data within two groups and showed significant improvement of all the parameters, where between group comparisons revealed higher improvement in Group B compared to the Group A.

Conclusion: Conventional physiotherapy techniques are more effective for improving pain and disability in patients with idiopathic adhesive 
capsulitis of shoulder joint than high grade Maitland mobilization technique.

Copy Right, IJAR, 2019,. All rights reserved.

\section{Introduction:-}

The term "capsulitis" or "frozen shoulder" refers to a common shoulder condition characterized by the global restriction in the shoulder range of motion in a capsular pattern. The capsular pattern in the shoulder is characterized by most limitation of passive lateral rotation and abduction. The presence of capsular pattern is necessary to give a diagnosis of shoulder Capsulitis. ${ }^{1}$ More recent evidence supports the idea that adhesive capsulitis is a combination of synovial inflammation and capsular fibrosis, which results in thickening and contracture of the inferior capsule rather than adherence, adhesive capsulitis as peri-arthritis scapula-humeral. In 1934, Codman coined the term frozen shoulder ${ }^{2 .}$ The incidence of frozen shoulder has been found to be two to four times higher in diabetics than in the general population. The estimated prevalence is $11-30 \%$ in diabetic patients and 2-10\% in non-diabetics ${ }^{3 .}$ The condition progresses in three stages: freezing (painful), frozen (adhesive) and thawing, and is often self-.limiting. Common conservative treatments include nonsteroidal anti-.inflammatory drugs, oral glucocorticoids, intra-articular glucocorticoid injections and/or physical therapy ${ }^{4}$ Conservative management strategies for frozen shoulder frequently include combination of varied types of interventions such as rest, medications, acupuncture, physical agents, postural or ergonomic advice, slings and range of motion exercise programs. Therapy includes manual therapy; ROM exercises, specific stretching and strengthening exercises and aerobic program and modalities are available such as interferential therapy, ultrasound, and hot therapy. There is no doubt that physiotherapy treatment is promising and cost effective treatment protocol ${ }^{5 .}$

\section{Hypothesis}

\section{Null Hypothesis}

There is no significant improvement in effectiveness of high grade Maitland mobilization technique to reduce pain and restore movement in patient with adhesive capsulitis of shoulder.

\section{Alternate hypothesis}

There is a significant improvement in effectiveness of high grade Maitland mobilization technique to reduce pain and restore movement in patient with adhesive capsulitis of shoulder.

\section{Methodology And Materials:-}

It was experimental study design; the sample was consisted of male and female who complain of idiopathic adhesive capsulitis, study was conducted Gonoshasthaya Samaj Vittik Medical College \& hospital and Gonoshasthaya Nagar Hospital, Dhaka. Study duration was one year and sample size were 40 are selected by maintained of exclusion and inclusion criteria, Material were used visual analogue scale (VAS). Shoulder pain disability index (SPADI), Outcome measured of pain and functional activity of shoulder joint. A pretested, modified, interviewer administrated, semi-structured questionnaire was used to collect the data. After collection of data of the respondents were organized. Data was entered into the computer into a data base in the software package Statistical package for the social science (SPSS) Version 20.0 and student $t$ test using descriptive statistics such as frequency, distribution, range, mean, and percentage. All scores and percentages was computed and presented in tabular form, charts, and graphs as appropriate. Further it was analyzed with the help of chi-square test and P-value. Finally the data was interpreted on the basis of study findings.

\section{Treatment Protocol}

Based on the selection criteria 40 patients were randomly assigned for the treatment into two groups.

GROUP A [n-20]:

High Grade Maitland Mobilization Technique.

\section{GROUP B [n-20]}

Conventional Physiotherapy Technique

Maitland mobilization:

5 minutes with 5 sets of glides per session for 2 weeks 


\section{Conventional Physiotherapy Technique:}

1. UST 5-6 Minutes (frequency 1.5-3 MHZ according to patient muscles depth, Intensity $0.8 \mathrm{watt} / \mathrm{cm}^{2}$ ), IRR or Hot pack 15-20 Minutes.

2. Myofascial trigger point release.

3. Pendulum Exercise.

4. Specific muscle stretching (hold for 15-20 minutes with stretched and rest for 10-15 minutes between each session).

5. Strengthening Exercise with resistance.

Data analysis and interpretation

Visual analogue scale

Paired t' test- group-a (high grade maitland mobilization technique)

\begin{tabular}{|c|c|c|c|}
\hline Groups & Mean & Standard Deviation & 't' Value \\
\hline Severity of pain (Before Treatment) & 8.20 & 0.70 & \multirow{2}{*}{18.41} \\
\hline Severity of pain (After Treatment) & 4.45 & 0.76 & \\
\hline
\end{tabular}

Paired ' $t$ ' test with 19 degrees of freedom and $5 \%$ as level of significance, the table ' $t$ ' value is 2.093 which was lesser than the calculated ' $t$ ' value 18.41. This test showed that there was significant effect of High Grade Maitland Mobilization Technique in reduction of pain with idiopathic adhesive capsulitis of shoulder joint.

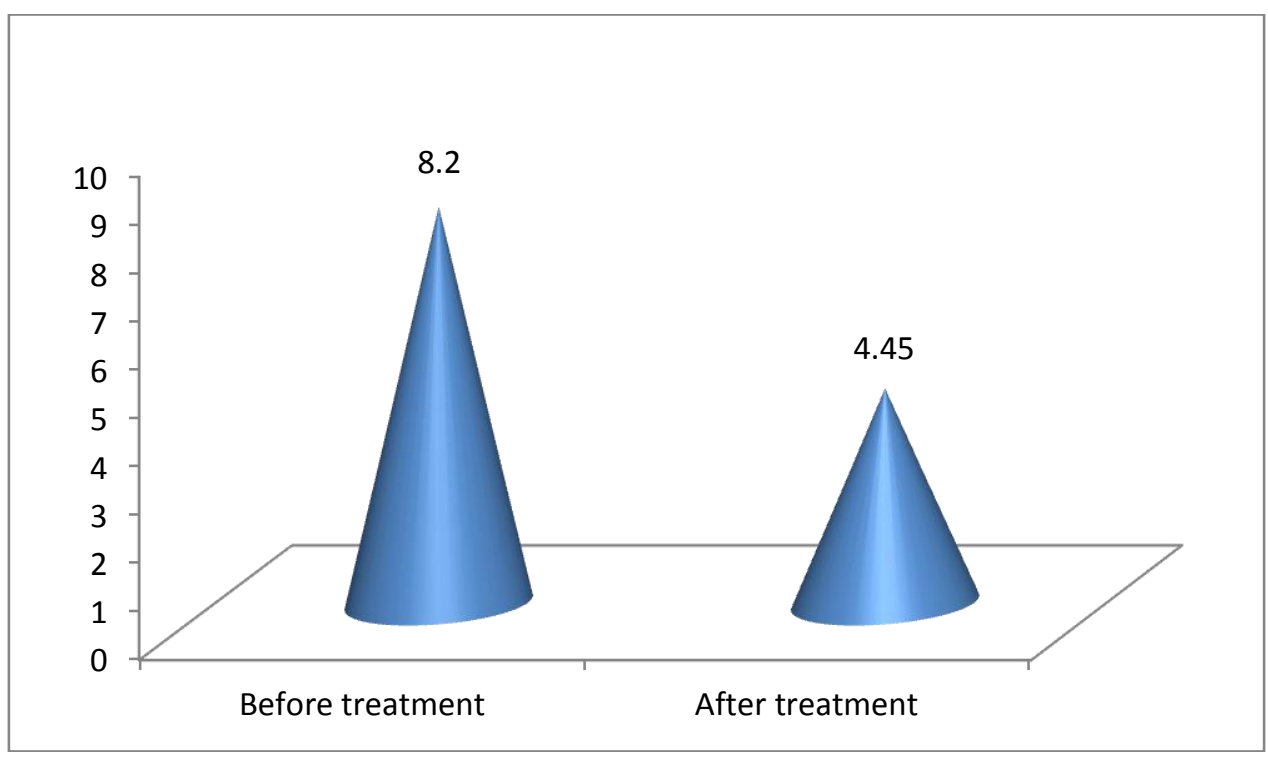

Visual Analogue Scale Paired ' $t$ ' Test Group A (High Grade Maitland Mobilization Technique)

Visual analogue scale paired ' $t$ ' test Group-b (conventional physiotherapy technique)

\begin{tabular}{|c|c|c|c|}
\hline Groups & Mean & Standard Deviation & 't' Value \\
\hline Severity of Pain (Before Treatment) & 8.10 & 0.72 & \multirow{2}{*}{27.91} \\
\hline Severity of Pain (After Treatment) & 3.45 & 0.83 & \\
\hline
\end{tabular}

Using Paired ' $t$ ' test with 19 degrees of freedom and 5\% as level of significance, the table ' $t$ ' value is 2.093 which was lesser than the calculated ' $t$ ' value 27.91. This test showed that there was significant effect of Conventional Physiotherapy Technique in reduction of pain with Idiopathic Adhesive Capsulitis. 


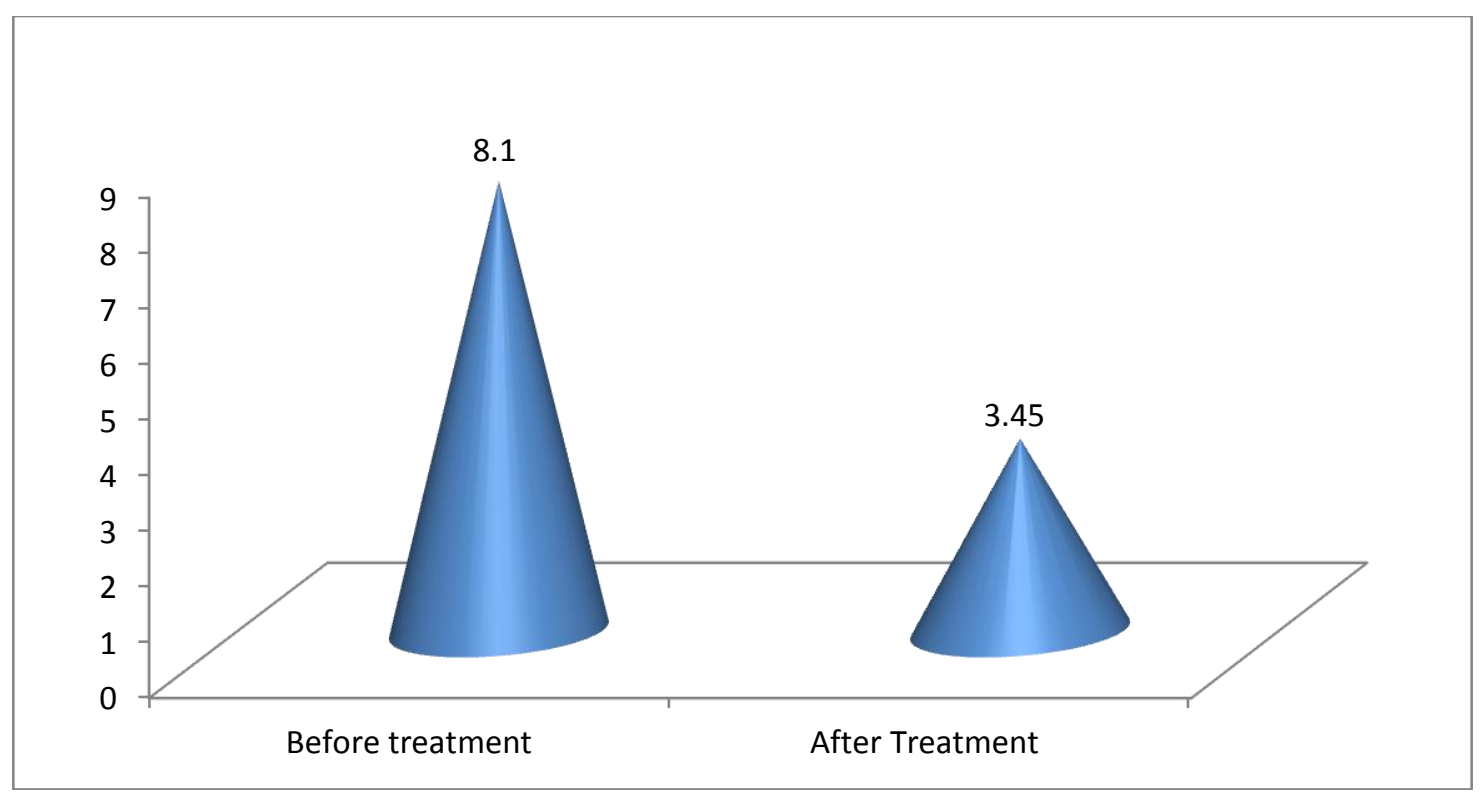

Figure: Visual Analogue Scale Paired T Test

Group B (Conventional Physiotherapy Technique)

Shoulder pain and disability scale paired ' $t$ ' test

Group- a (high grade maitland mobilization technique)

\begin{tabular}{|c|c|c|c|}
\hline Groups & Mean & Standard Deviation & 't' Value \\
\hline $\begin{array}{c}\text { Shoulder Pain Disability Index } \\
\text { (Before Treatment) }\end{array}$ & 13.40 & 0.88 & 37.9966 \\
\hline $\begin{array}{c}\text { Shoulder Pain Disability Index } \\
\text { (After Treatment) }\end{array}$ & 6.95 & 1.10 & \\
\hline
\end{tabular}

Paired ' $t$ ' test with 19 degrees of freedom and 5\% as level of significance, the table ' $t$ ' value is 2.093 which was lesser than the calculated ' $t$ ' value 37.9966. This test showed that there was significant effect of High Grade Maitland Mobilization Technique in reduction of pain with idiopathic adhesive capsulitis of shoulder joint.

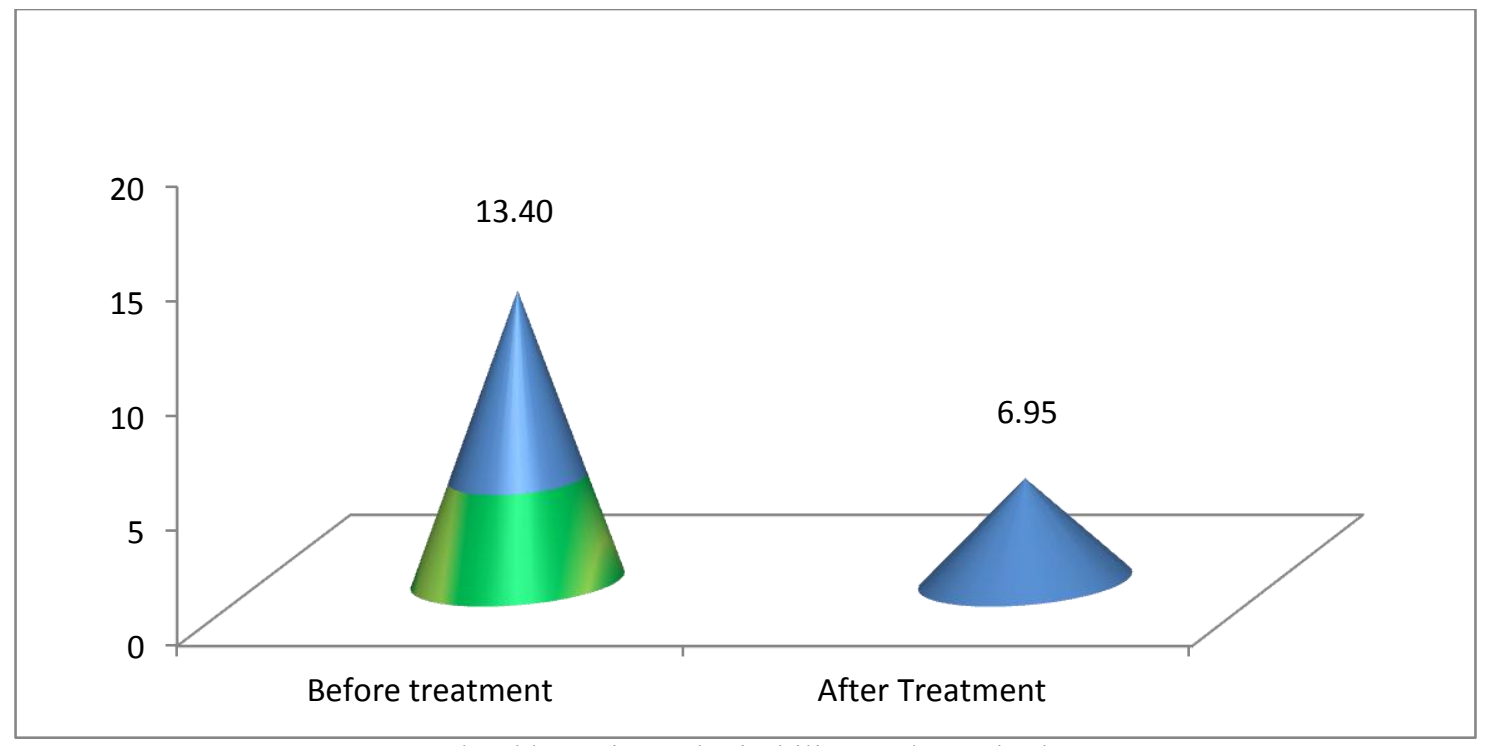

Figure: Shoulder Pain And Disability Scale Paired ' $T$ ' Test GROUP A (High Grade Maitland Mobilization Technique) 
Shoulder pain and disability scale paired 't' test

Group b (conventional physiotherapy technique)

\begin{tabular}{|c|c|c|c|}
\hline Groups & Mean & Standard Deviation & 't' Value \\
\hline $\begin{array}{c}\text { Shoulder Pain Disability Index (Before } \\
\text { Treatment) }\end{array}$ & 12.95 & 2.24 & \multirow{2}{*}{13.9269} \\
\hline $\begin{array}{c}\text { Shoulder Pain Disability Index (After } \\
\text { Treatment) }\end{array}$ & 5.95 & 0.60 & \\
\hline
\end{tabular}

Paired t' test with 19 degrees of freedom and 5\% as level of significance, the table $t$ ' value is 2.093 which was lesser than the calculated ' $t$ ' value 13.93. This test showed that there was significant effect of Conventional Physiotherapy Technique in reduction of pain with Idiopathic Adhesive Capsulitis of shoulder joint.

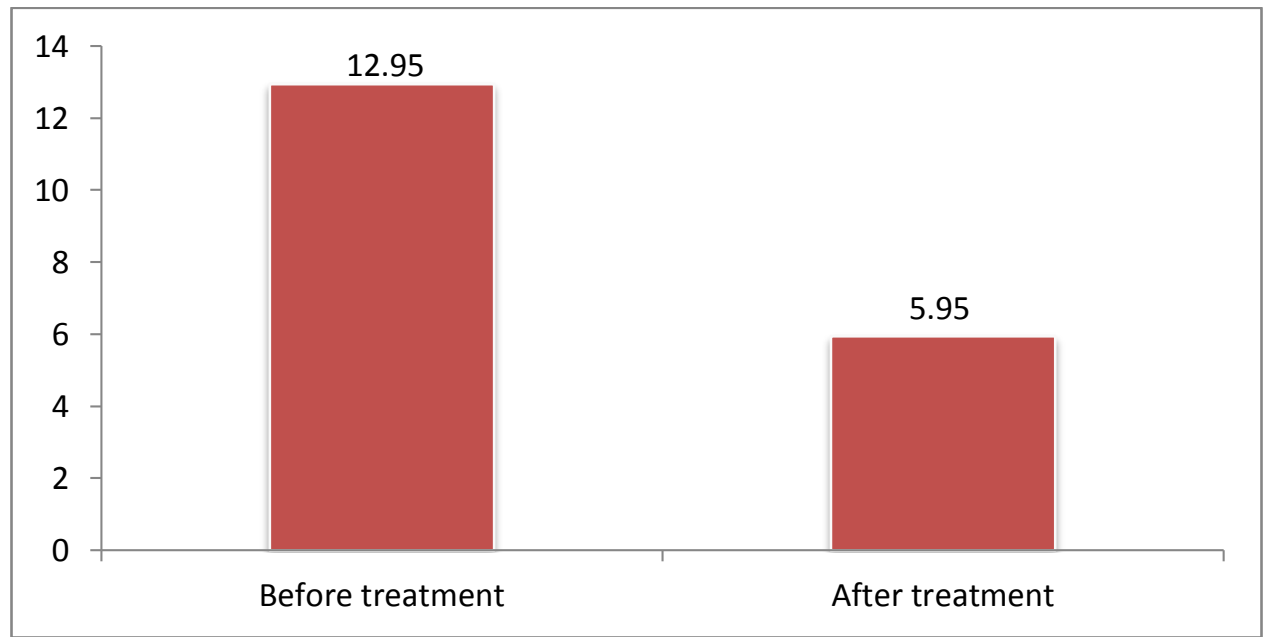

Figure: shoulder pain \& disability scale paired $t$ test

Group a (high grade maitland mobilization technique)

Visual analogue scale for pain unpaired ' $t$ ' test

Pretest values of group a vs group $b$.

\begin{tabular}{|c|c|c|c|}
\hline Groups & Mean & Standard Deviation & 't' Value \\
\hline Group A & 8.20 & 0.70 & \multirow{2}{*}{0.4472} \\
\hline Group B & 8.10 & 0.72 & \\
\hline
\end{tabular}

Pre-test values of Group A and B is analyzed by unpaired ' $t$ ' test. The calculated ' $t$ ' value is 0.4472 , which is lesser than the ' $\mathrm{t}$ ' value 2.024 at $5 \%$ level of significance and 38 degrees of freedom. This test showed that there was no significant difference in reduction of pain between the effect of Group A and B.

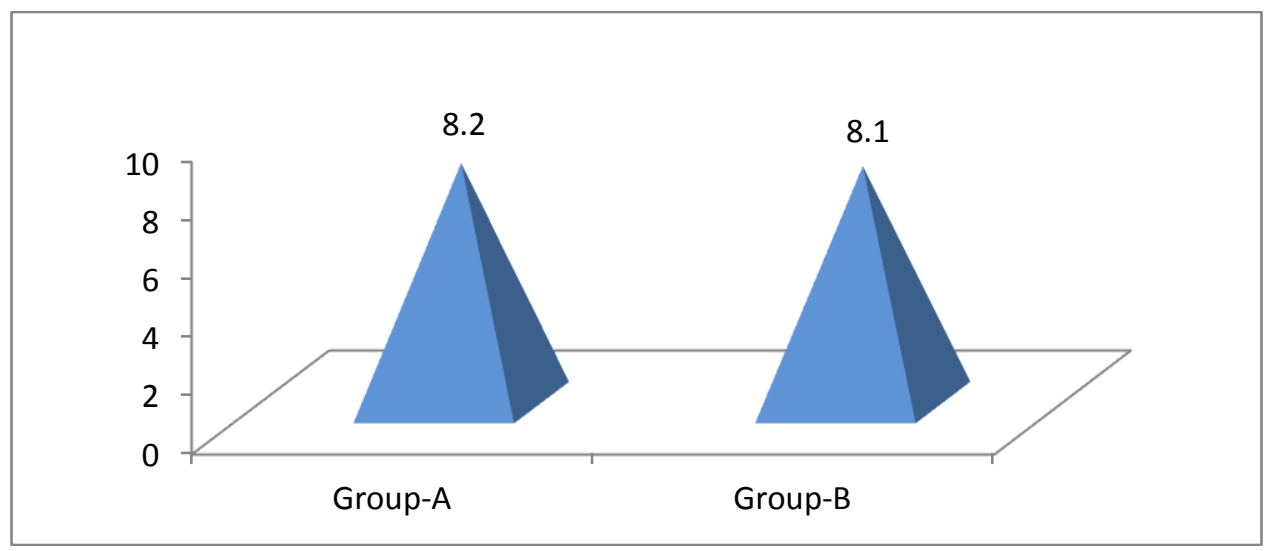

Figure: Visual Analogue Scale For Pain Unpaired T Test 
Pretest Values of Group A Vs Group B

Visual analogue scale for pain unpaired ' $t$ ' test

Posttest values of group a vs group b

\begin{tabular}{|c|c|c|c|}
\hline Groups & Mean & Standard Deviation & 't' Value \\
\hline Group A & 4.45 & 0.76 & \multirow{2}{*}{3.9874} \\
\hline Group B & 3.45 & 0.83 & \\
\hline
\end{tabular}

Post-test values of Group A and B is analyzed by unpaired ' $t$ ' test. The calculated ' $t$ ' value is 3.9874 , which is greater than the ' $\mathrm{t}$ ' value 2.024 at $5 \%$ level of significance and 38 degrees of freedom. This test showed that there was significant difference in reduction of pain between the effect of Group A and B.

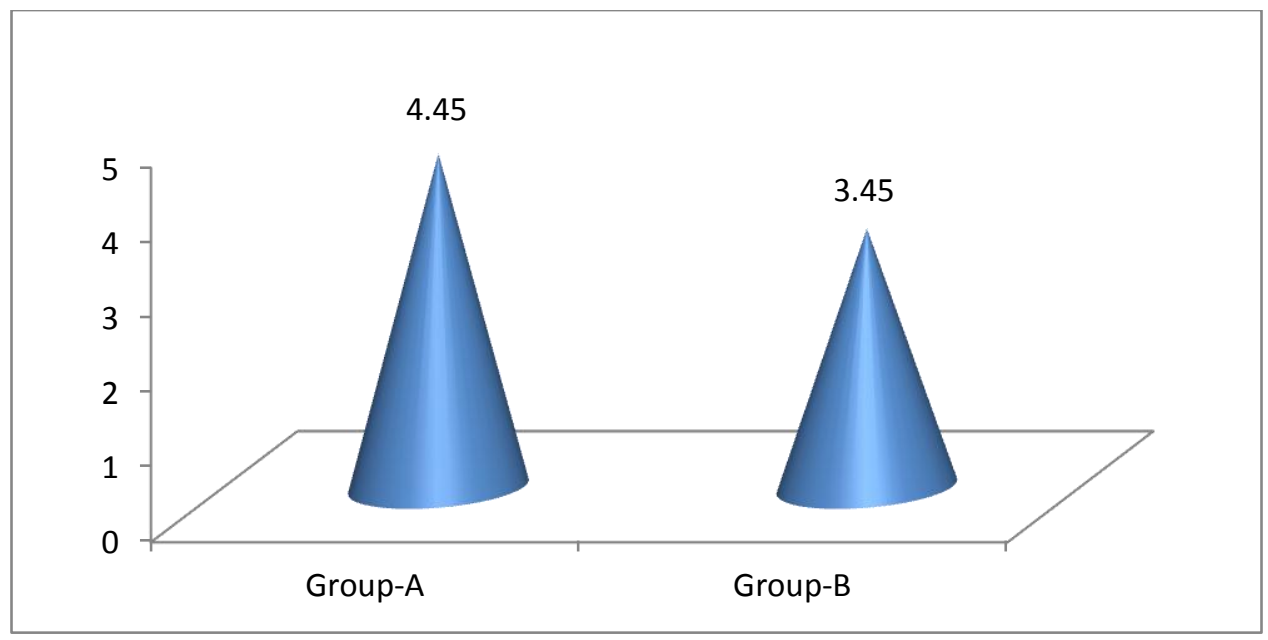

Figure: visual analogue scale for pain unpaired ' $\mathrm{t}$ ' test

Post test value of group a vs group b

Shoulder disability index unpaired ' $t$ ' test

Pre test values of group a vs group b

\begin{tabular}{|c|c|c|c|}
\hline Groups & Mean & Standard Deviation & 't' Value \\
\hline Group A & 13.40 & 0.88 & \multirow{2}{*}{0.1921} \\
\hline Group B & 13.45 & 0.76 & \\
\hline
\end{tabular}

Pre-test values of Group A and B is analyzed by unpaired ' $t$ ' test. The calculated ' $t$ ' value is 0.1921 , which is lesser than the ' $\mathrm{t}$ ' value 2.024 at $5 \%$ level of significance and 38 degrees of freedom. This test showed that there was no significant difference in improvement of function between the effect of Group A and B to reduction of disability.

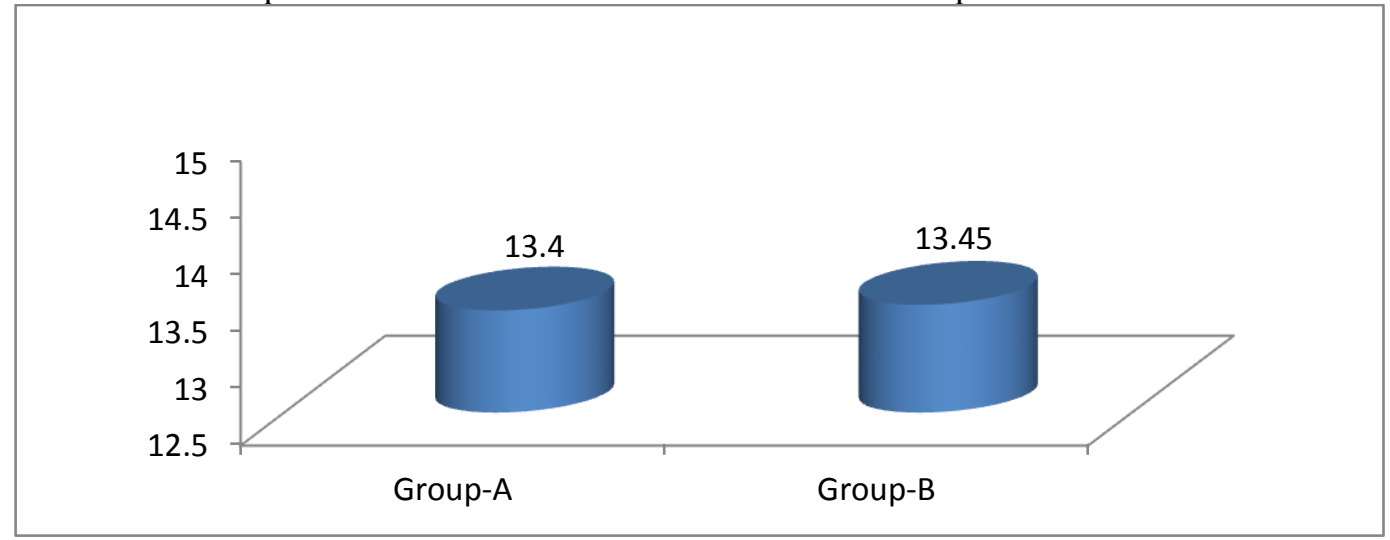

Figure: Shoulder Disability Indes Unpaired ' $T$ ’ Test

Pre Test Values Of Group A Vs Group B 
Shoulder disability index unpaired' $t$ ' test

Post test values of group a vs group b

\begin{tabular}{|c|c|c|c|}
\hline Groups & Mean & Standard Deviation & ' $t$ ' Value \\
\hline Group A & 6.95 & 1.10 & \multirow{2}{*}{3.2085} \\
\hline Group B & 6.05 & 0.60 & \\
\hline
\end{tabular}

Pre-test values of Group A and B is analyzed by unpaired ' $t$ ' test. The calculated ' $t$ ' value is 3.2085, which is greater than the ' $t$ ' value 2.024 at $5 \%$ level of significance and 38 degrees of freedom. This test showed that there was a significant difference in improvement of function between the effect of Group A and B to reduction of disability.

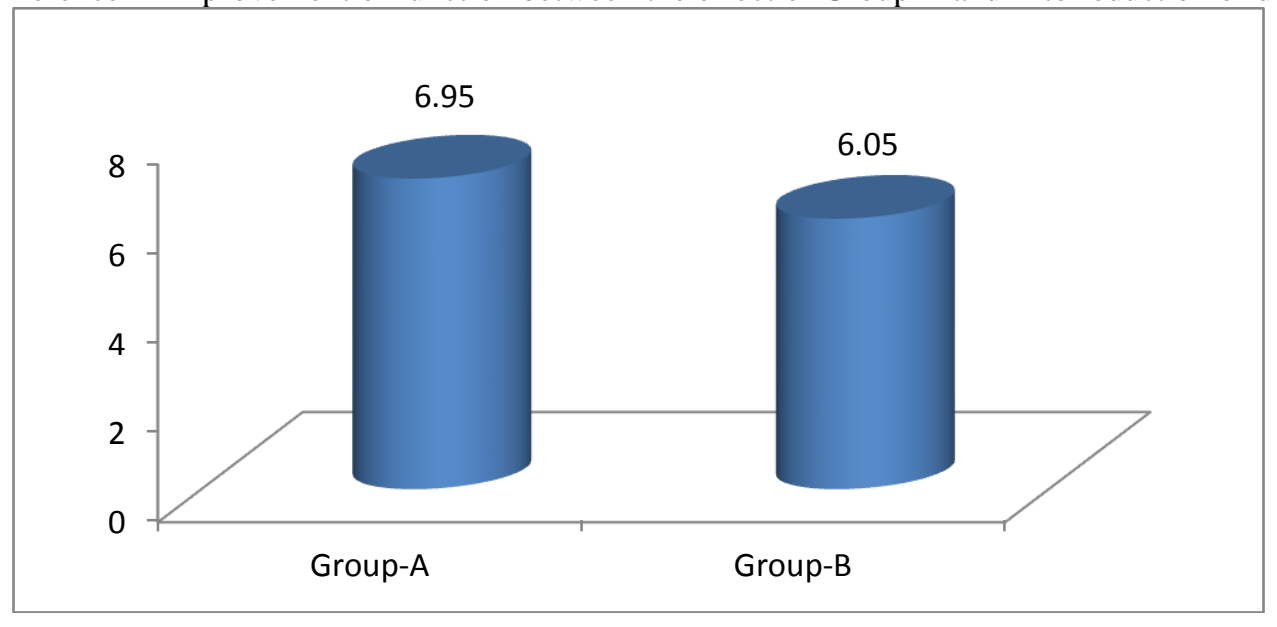

Figure: shoulder disability index unpaired ' $t$ ' test Post test values of group a vs group $b$

\section{Discussion:-}

Shoulder adhesive capsulitis is a very common term among the people of Bangladesh. The present study was designed to know the effectiveness of high grade Maitland mobilization technique in patients with idiopathic adhesive capsulitis. 40 subjects were selected who fulfilled the predetermined inclusive and exclusive criteria. The subjects were divided into two groups, 20 persons in each groups. Groups were named as Group A and Group B. We were applied high grade Maitland mobilization technique in Group A and conventional Physiotherapy Technique in Group B.

The mean age group with Standard deviation (SD) of this study were $45.63 \pm 8.018$ years with a range from 35 to 65 years and 35-39 years age groups were more affected by this condition. More of the respondents were female $(62.5 \%)$ and also more of the respondents were married $(92.5 \%)$. Secondary $(35 \%)$ passed people were more and people who are related with housewife job, they are mostly affected (40\%) by this condition. Deformity level were very less, just only $12.5 \%$ and Right shoulder is maximally affected $(82.5 \%)$. Most of the patient suffered by continuous pain (55\%) and Pain were feeling more at morning $(75 \%)$. Muscle deformity were found in $95 \%$ of the patients and maximum patient were visited doctors $(67.5 \%)$ at their own will to get ride of this condition. History of trauma and Diabetes Mellitus were found in a very less case and this were only $7.5 \%$ and $32.5 \%$. This study found highly significant association between any muscle of the deformity and types of pain $(\mathrm{p} \leq 0.02)$.

The Paired ' $t$ ' test analysis for the pre-test and post-test variable for the visual analogue scale for measuring shoulder pain which is shown in table I and II. Both the groups shows a significant difference between the pre-test and posttest values. The ' $t$ ' value for the Group A (High Grade Maitland Mobilization Technique) is 18.41 and the $t$ ' value for the Group B (Conventional Physiotherapy Technique)) is 27.91. The paired ' $t$ ' test analysis for the pre-test and post-test variables for the shoulder pain and disability scale for measuring shoulder pain which is shown in table III and IV. Both the groups shows a significant difference between the pre-test and post-test values. The ' $t$ ' value for the group A (High Grade Maitland Mobilization Technique) is 37.9966 and for the group B (Conventional Physiotherapy Technique) is 13.9269. 
While analyzing the outcome measures of this study, it was observed that both the groups have shown significant improvement over time but conventional physiotherapy method showed more effective than high grade Maitland mobilization technique.

\section{Conclusion:-}

The purpose of the study were effectiveness of high grade maitland mobilization technique in patient with idiopathic adhesive capsulitis. We were chosen 40 subjects total for the study and applied two different method between two groups containing 20 subjects each group. Applied high grade maitland mobilization technique to Group A and conventional physiotherapy techniques (UST, IRR or Hot Pack, Passive Movement, Home Advice etc.) to Group B subjects. Before treatment and after treatment values are analyzed in VAS (Visual Analogue Scale) and Shoulder pain and disability scale. The result showed that there were a significant difference between two techniques in the reduction of pain and disability in patient with idiopathic shoulder adhesive capsulitis. This study concluded that high grade maitland mobilization were effective but conventional physiotherapy technique were more effective than high grade maitland mobilization technique.

\section{Bibliography:-}

1. Kumar A, Kumar S, Aggarwal A, Kumar R, Das PG, Effectiveness of Maitland Techniques in Idiopathic Shoulder Adhesive Capsulitis, International Scholarly Research Network(ISRN) Rehabilitation, v. 2012, p.8.

2. URL: http://dx.doi.org/10.5402/2012/710235

3. Hai V. Le, Stella J. Lee, Ara Nazarian, and Edward K. Rodriguez, Adhesive capsulitis of the shoulder: review of pathophysiology and current clinical treatments, journal of PMC, v.9(2); 2017

4. URL: https://www.ncbi.nlm.nih.gov/pmc/articles/PMC5384535/

5. Ruchita Banseria, Sunil Kumar Gothwal, Frozen shoulder and their risk factor in diabetic population prevalence study from north west India, Indian Journal of Scientific Research, 7(7):10-12 - August 2018. URL: https://www.researchgate.net/publication/327201720_FROZEN_SHOULDER

6. Hui Bin Yvonne Chan, Pek Ying Pua and Choon How How. Physical therapy in the management of frozen shoulder, Singapore Med J,v.58(12); 2017 Dec. https://www.ncbi.nlm.nih.gov/pmc/articles/PMC5917053/

7. Sonu Punia and Sushma, Effect of Physiotherapy Treatment on Frozen Shoulder: a Case Study, Indian Journal of Physiotherapy and Occupational Therapy. January-March 2015, Vol. 9, No. 1 URL: https://www.researchgate.net/publication/281612142_. 